\title{
Uncovering Vote Trading Through Networks and Computation
}

Ulrich Matter

(SEPS-HSG, SIAW, University of St. Gallen)

Omar A. Guerrero

(Institute for New Economic Thinking and CABDyN Complexity Centre, University of Oxford)

VfS Jahrestagung, Vienna, 5/09/2017 


\section{Anecdotal evidence \& qualitative studies}

"This will be sort of a buddy vote. I know cigarettes are harmful and I wouldn't touch them myself. But a lot of my friends are concerned about this, because tobacco means a lot to the economy of their areas. They do things for me when I need it, and I'll do this for them. Frankly, it's just a matter of helping out your friends."

(Anonymous Member of Congress on vote trading in the context of a bill deregulating cigarette advertisement; Kingdon 1989:100) 


\section{A simple theory of vote trading}




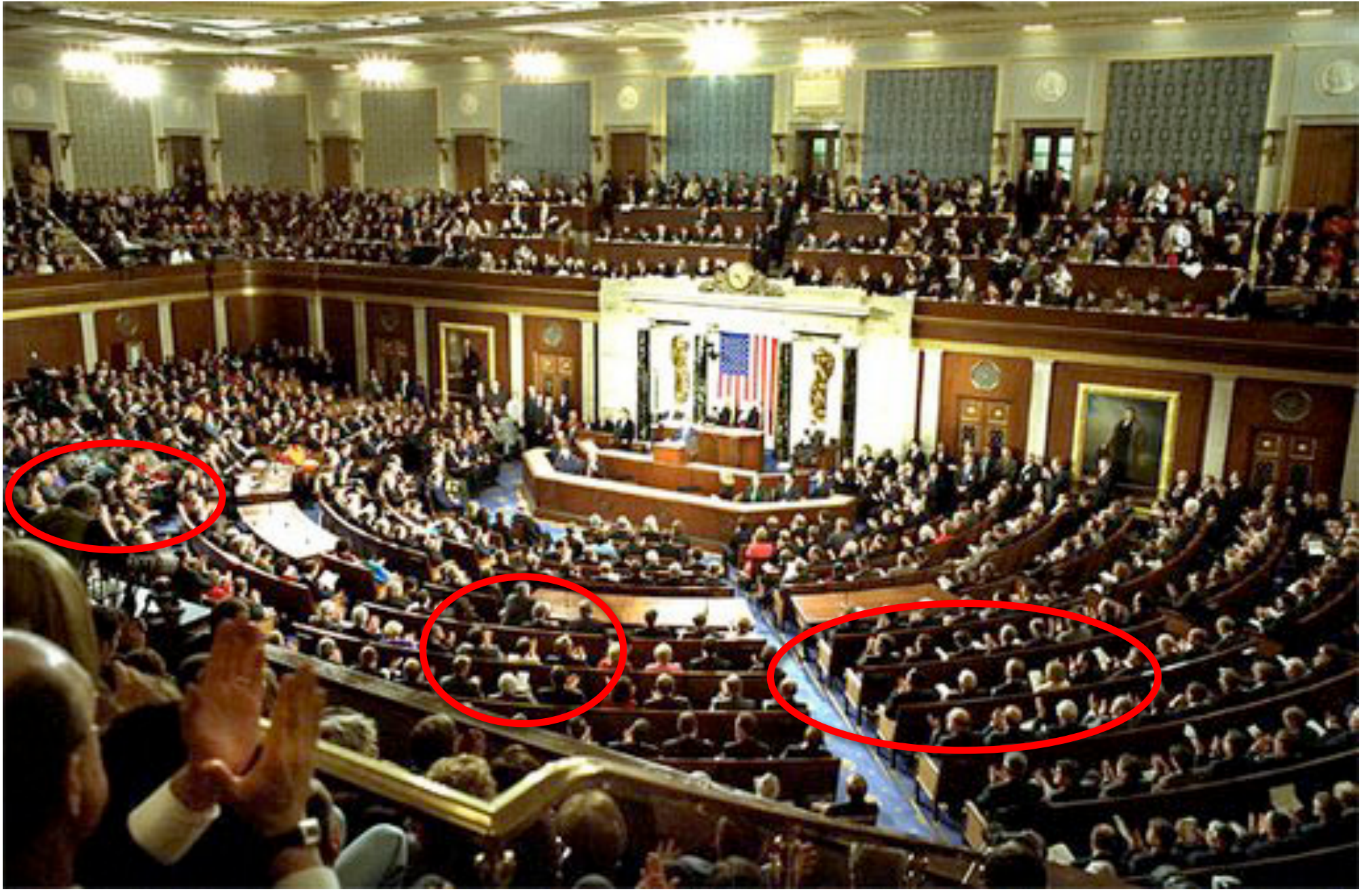




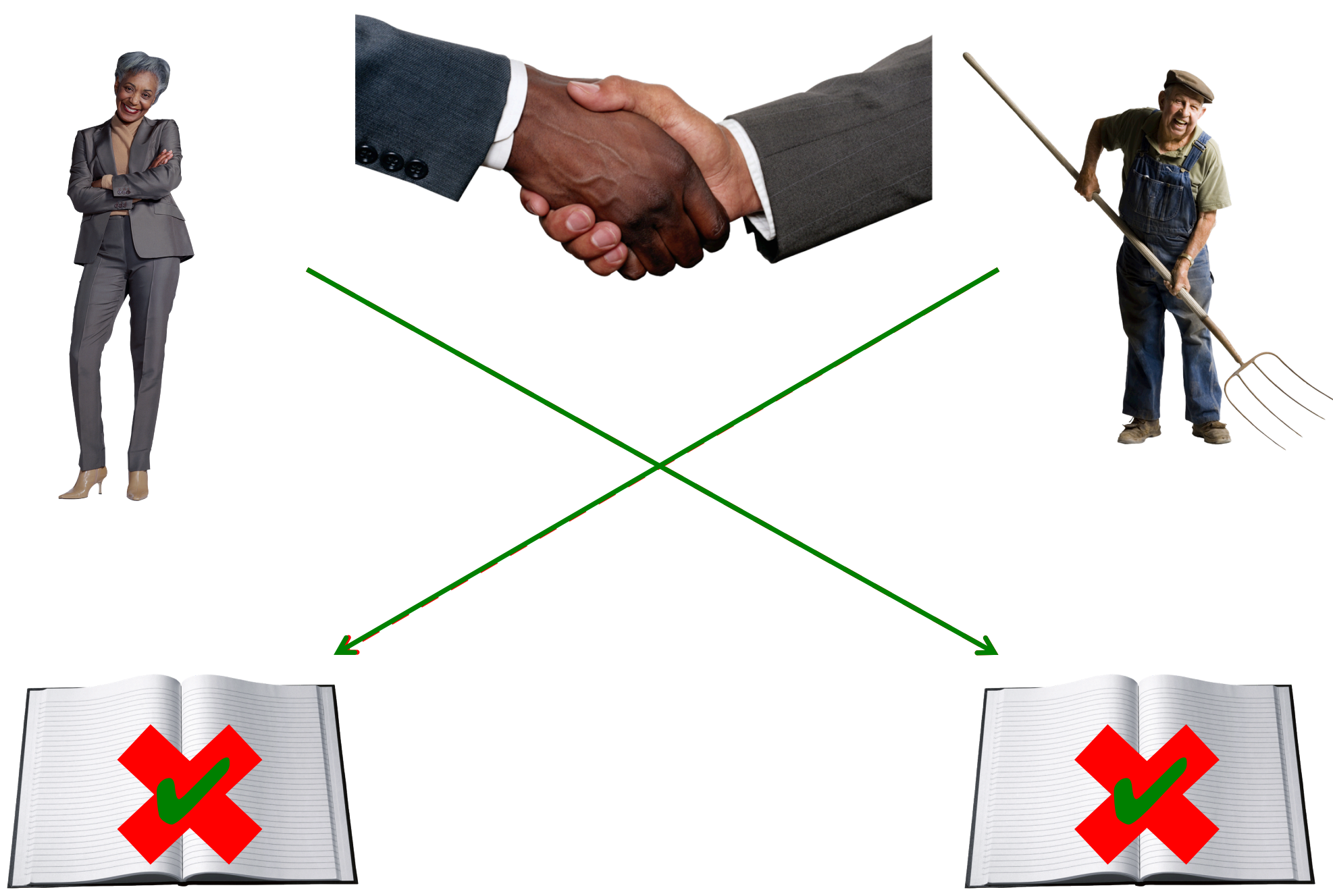




\section{Theoretical key points}

- Incentives to trade votes are stronger if the outcome of the vote is expected to be narrow.

- A traded vote is a deviation from a legislator's 'preferred' policy position. 


\section{Literature and existing evidence}




\section{Literature}

- Large theoretical literature in political economics and political science (e.g., Buchanan and Tullock 1962, Tullock 1970, Bernholz 1973).

- Very few empirical studies with a reasonable test to identify logrolling. (Stratmann 1992, Stratmann 1995, Cohen and Malloy 2014)

- A lot of open questions:

- How prevalent is vote trading?

- How does it evolve?

- How stable is it?

- What are it's driving factors? 


\section{Previous econometric approaches}

"To test for the presence of logrolling using [this method], one must be able to identify the particular issues on which trading takes place."

"Thousands of votes are taken during a session of Congress, many of which involve no logrolling. Moreover, the potential patterns of trades are limitless."

(Stratmann 1992:1164; AER) 


\section{A novel approach to detect vote trading}




\section{Consistence with theory}

1. Incentives to trade are higher the narrower vote outcomes are (perceived to be).

2. A traded vote is a deviation from the legislator's 'preferred' policy position.

3. Such a deviation must be in favor of another legislator's preferences towards the bill.

4. These deviations in favor of other legislators are reciprocal. 


\section{Three ingredients}

i. How did legislators vote on various bills?

$\rightarrow$ Roll call matrix $\mathbb{V}$

ii. Information on legislators and bills.

$\rightarrow \mathrm{X}$

iii. Who has strong preferences for which bill?

$\rightarrow$ 'Signaling' matrix $\mathbb{S}$ 
1) Detect deviations from 'usual voting behavior'

a. Estimate a simple econometric model that aims to explain voting decisions in $\mathbb{V}$

b. Use the estimated model to predict the legislators' propensity to vote Yes in votes with narrow outcomes.

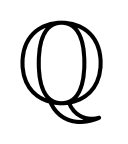


1) Detect deviations from 'preferred' positions

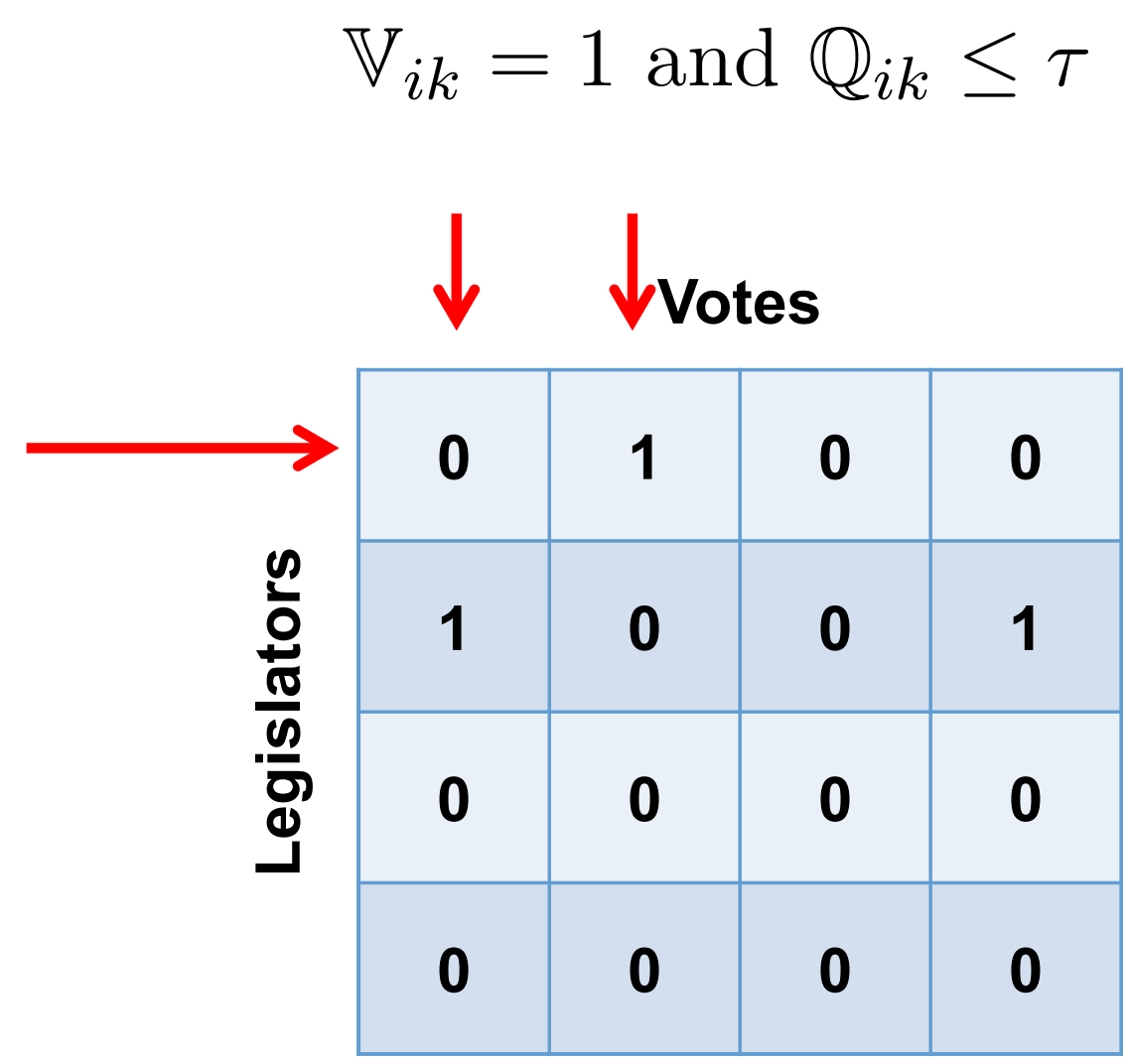




\section{2) Draw the directed deviation network (DDN)}

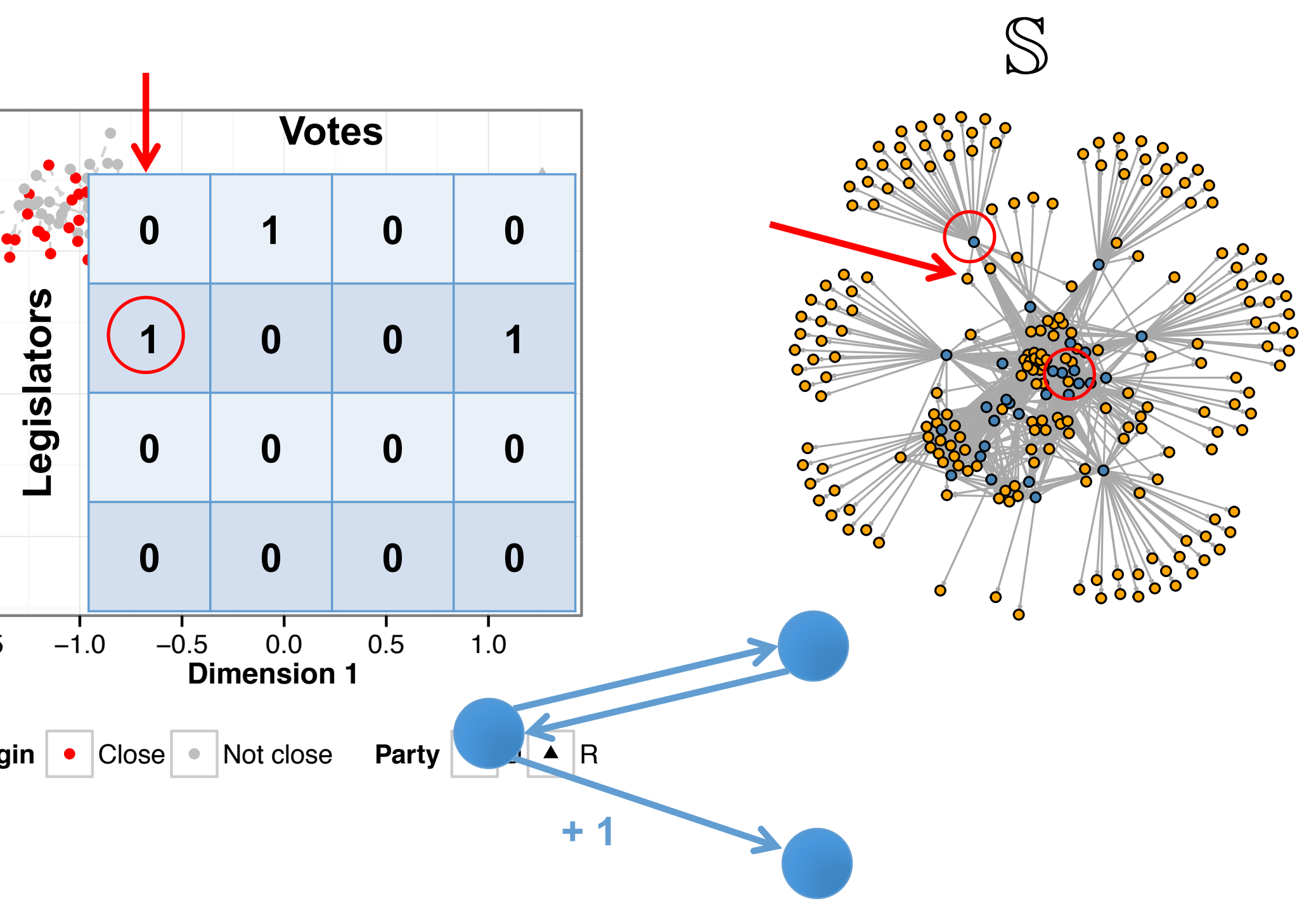


2) Draw the directed deviation network (DDN)

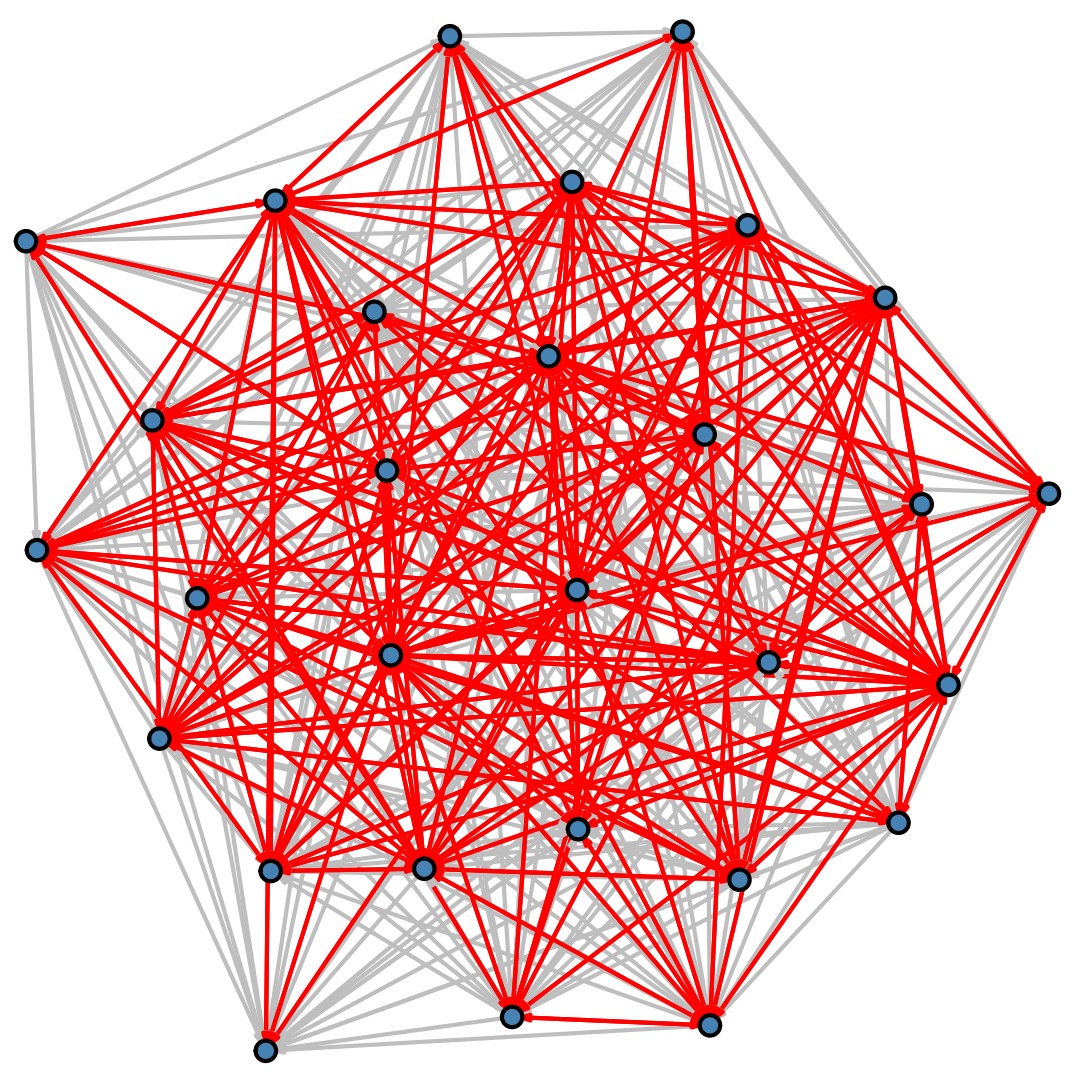




\section{3) Reciprocity in directed weighted networks}

$$
\begin{gathered}
w_{i j}^{\overleftrightarrow{\leftrightarrow}}=\min \left[\mathbb{W}_{i j}, \mathbb{W}_{j i}\right]=w_{j i}^{\overleftrightarrow{ }} \\
f_{i}(\mathbb{W})= \begin{cases}1 & \text { if } \sum_{j \neq i}^{N} w_{i j}^{\leftrightarrow}>0 \\
0 & \text { otherwise }\end{cases} \\
R=\sum_{i}^{N} f_{i}(\mathbb{W}) \\
W=\sum_{i}^{N} \sum_{j \neq i}^{N} \mathbb{W}_{i j} \\
t=\frac{2 R}{W}
\end{gathered}
$$




\section{4) Null hypothesis, logrolling index, VTN}

a. Compare $t$ with the expected value of $t$ under the null hypothesis.

- Null network has same properties as the DDN based on real data.

- Legislators' deviations, however, are drawn randomly.

$\ell=\frac{t-\bar{t}_{0}}{1-\bar{t}_{0}}$

(Squartini et al. 2013, Sci. Rep.)

b. Compute jackknife standard errors by removing edges (Newman 2003, Phys Rev E)

c. Extract the Vote Trading Network (VTN) 


\section{A first application}

The anatomy of vote trading in the U.S. Congress 


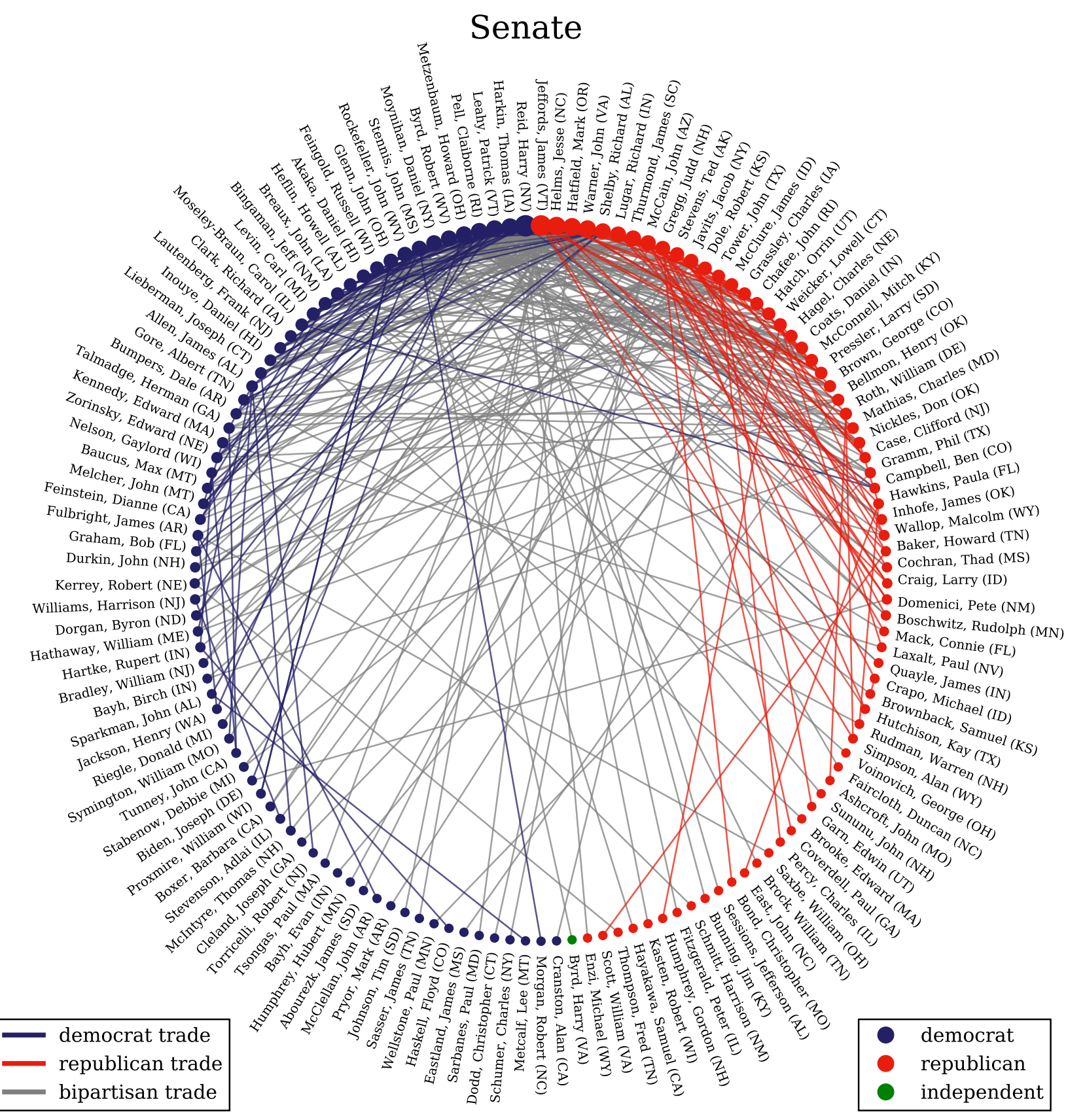




\section{Conclusions}

- Limitations

- Other forms of logrolling

- Limits of validation

- Small samples

- Potential

- Scalable (different legislatures, different time frames, ...)

- It is flexible (specification of matrix S, deviation detection, ...)

- Combination with qualitative research and previous econometric approaches 


\section{Questions? Thank you!}

Uncovering Vote Trading Through Networks and Computation Ulrich Matter

\section{http://umatter.github.io}

VfS Jahrestagung, Vienna, 5/9/2017 